\title{
Un cuadro inédito de San Miguel Arcángel, obra de Giacomo Farelli, en Alcalá de Henares
}

\author{
An unprecedent painting of Saint Michael the Arcangel, \\ by Giacomo Farelli, in Alcalá de Henares \\ Josué LLULL PEÑALBA \\ Centro Universitario Cardenal Cisneros, \\ adscrito a la Universidad de Alcalá
}

Recibido: 28-III-2017

Aceptado: 15-VI-2017

RESUMEN: En este artículo se da a conocer la existencia de un cuadro, hasta ahora inédito, que representa a San Miguel Arcángel venciendo al demonio. Es propiedad de la congregación de los Hermanos Maristas y se conserva en su casa provincial de Alcalá de Henares. Una reciente restauración ha permitido atribuirlo a Giacomo Farelli, artista barroco vinculado a la Escuela Napolitana de Pintura de la segunda mitad del siglo XVII. El cuadro tiene un notable interés por su calidad y por la escasez de obras de Farelli que hay en España. La publicación de este trabajo de investigación pretende contribuir a un mayor conocimiento de la figura de este pintor y de las fructíferas relaciones histórico-artísticas desarrolladas entre España e Italia.

Palabras clave: San Miguel Arcángel, Giacomo Farelli, Pintura Barroca Napolitana, Hermanos Maristas, Alcalá de Henares.

ABSTRACT: This paper is intended to give some information about an unprecedented painting representing The Archangel Saint Michael defeating Satan. It belongs to the Marist Brothers community and is kept in their provincial house in Alcalá de Henares. As a result of a recent restoration the authorship can be attributed to Giacomo Farelli, a Baroque artist linked to the Neapolitan School of Painting in the second half of the 17th Century. It is a picture of interest because of its qualities and the scarcity of Farelli's paintings located in Spain. The publication of this research work aims at contributing to improve the knowledge about this painter and the profitable historic artistic relationships between Spain and Italy.

Key words: Saint Michael the Archangel, Giacomo Farelli, Baroque Neapolitan Painting, Marist Brothers, Alcalá de Henares.

\section{ANÁLISIS FORMAL E ICONOGRÁFI- CO DE LA OBRA}

La congregación religiosa de los Hermanos Maristas de la provincia canónica Ibérica posee un gran cuadro con la imagen de San Miguel Arcángel, de indudable estilo barroco y segura afiliación a la Escuela Napolitana de pintura del último tercio del siglo XVII (Fig. 1). El cuadro tiene una historia incierta, ha sido restaurado hace pocos años y actualmente se encuentra en la Casa 


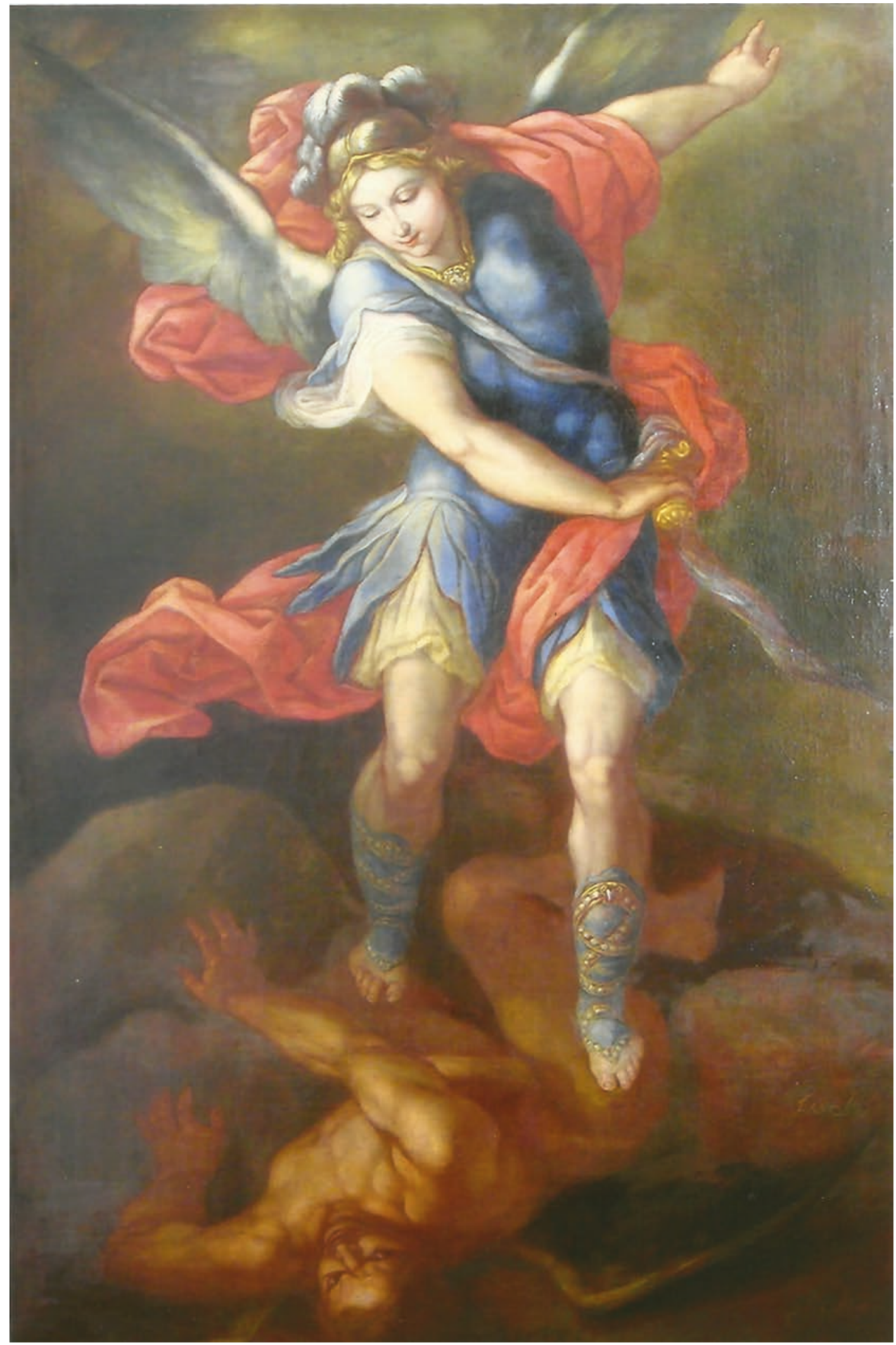

- Fig. 1. Giacomo Farelli. San Miguel Arcángel venciendo al demonio. Hacia 1690. Óleo sobre lienzo, 175,5 x $121 \mathrm{~cm}$. Alcalá de Henares, Casa provincial de la congregación de los Hermanos Maristas. Foto del autor. 
Provincial que dicha congregación tiene en la ciudad de Alcalá de Henares ${ }^{1}$.

Se trata de un óleo sobre lienzo de 175,5 $\mathrm{cm}$ de alto por $121 \mathrm{~cm}$ de ancho, firmado en el ángulo inferior derecho con las letras "Fareli", que identifican al pintor italiano Giacomo Farelli². El lienzo es de lino, forrado con tres paños cosidos, y está enclavado sobre un bastidor de madera con travesaño horizontal central, que no es el original. Conserva un marco de madera tallada, articulado por dos molduras doradas con pan de oro, y una calle intermedia convexa, pintada de color rojizo. Es seguramente de época posterior puesto que no corresponde al lienzo, ni por holgura ni por estilo.

El cuadro tiene como figura central al arcángel San Miguel, que se caracteriza como un joven rubio, alado y de gran belleza. Se muestra en actitud triunfante, vestido como un soldado romano envuelto en un manto rojo que ondea al viento. Está revestido de atributos militares: un casco metálico adornado con plumas, una coraza de cuero azul cerúleo con faldellín, sobrepuesta a una camisa blanca y una femoralia amarilla que dejan entrever una poderosa musculatura; con la mano derecha empuña una espada, todavía envainada, mientras con la izquierda señala hacia atrás, al cielo. Su mirada se dirige hacia abajo, donde se encuentra un ser monstruoso desnudo, tendido sobre un suelo rocoso; el santo le está pisoteando para significar su victoria, enfatizada por la po-

${ }^{1}$ La Provincia Ibérica Marista está formada por la provincia de Cáceres, las comunidades autónomas de Castilla La Mancha, Madrid, Aragón, La Rioja, la Comunidad Foral de Navarra, el País Vasco y dos obras sociales en Rumanía. El Consejo Provincial y otros órganos directivos de la congregación tienen su sede en la mencionada casa de Alcalá de Henares.

2 Giacomo Farelli (1629-1706) utilizó distintas variantes de su nombre para firmar sus obras: "Farrelli", "Farellus", "Farello", “Fariello" o la que aquí encontramos, "Fareli". Como Caballero de la Orden de Malta, en ocasiones añadió a su nombre una cruz de San Juan de Jerusalén, la inicial de Cavaliere o el epíteto Eques. tente anatomía de sus piernas, protegidas por grebas.

La imagen se ajusta a la representación tradicional de San Miguel y se inspira en modelos italianos precedentes difundidos a través de grabados. La variante más distintiva del cuadro firmado por Farelli es la posición del brazo derecho, cruzado sobre el cuerpo y con la mano sujetando la empuñadura de la espada. Esta postura es un recurso habitual en la obra de Miguel Ángel y fue reinterpretada numerosas veces por otros artistas de los siglos XVI y XVII. Uno de los ejemplos más próximos al cuadro que nos concierne es precisamente un San Michele Arcangelo de Marco Pino, realizado en 1573 para la iglesia de Sant'Angelo a Nilo de Nápoles (Fig. 2). Este pintor, originario de Siena, se estableció

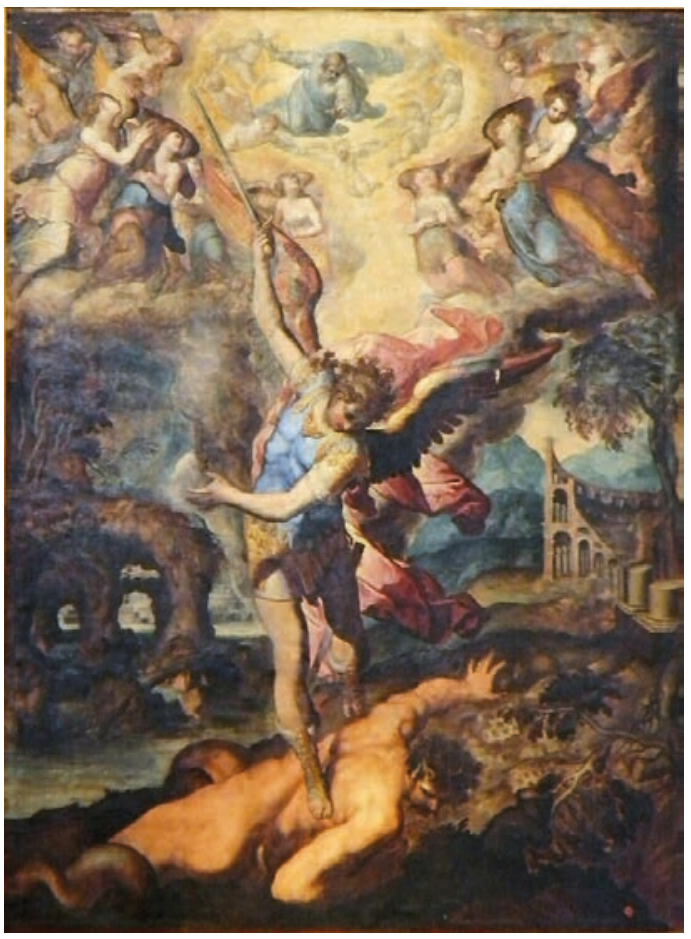

- Fig. 2. Marco Pino. San Michele Arcangelo. 1573. Nápoles, iglesia de Sant'Angelo a Nilo. Foto de it.wikipedia.org.

en la ciudad partenopea en 1557 y allí se convirtió en uno de los principales transmisores de la maniera del Buonarroti, que conocía merced a una estancia desarrollada previamente en Roma, donde trabajó con Daniele 
da Volterra ${ }^{3}$. En la imagen de la iglesia de Sant'Angelo, San Michele también cruza un brazo sobre el cuerpo y echa hacia atrás el opuesto, que en esta ocasión es el que maneja la espada. La disposición abierta de las alas, los detalles de la vestimenta y el manto rojo ondulante son desde luego muy parecidos a los del cuadro de los maristas, aunque dispuestos en sentido inverso.

Otra probable fuente de inspiración podría ser una estampa del grabador francés Philippe Thomassin que representa La caída de los ángeles rebeldes (1618), de la cual se conserva una copia en la National Gallery of Art de Washington. Además de la posición de las alas y el detalle del brazo atravesado, de nuevo en sentido inverso, existe un gran parecido en la colocación del otro brazo y en la figura del personaje caído en el centro de la zona inferior (Fig. 3) ${ }^{4}$. Un precedente aún más cercano en el tiempo lo tenemos en el espectacular lienzo del mismo tema pintado por Luca Giordano en 1663, que se conserva en la Gemäldegalerie de Berlín, aunque en esta ocasión el arcángel sujeta una lanza en vez de una espada. Por último, el propio Giacomo Farelli imitó la posición del brazo cruzado sobre el cuerpo en una pintura al fresco titulada El milagro de la mula (1667), que forma parte de la decoración del Santuario de Santa María della Croce en Roio.

La postura comentada provoca un forzado escorzo en el hombro de San Miguel y

${ }^{3}$ F. SRICCHIA SANTORO y A. ZEZZA, Marco Pino: un protagonista della maniera moderna a Napoli, Napoli, 2003; A. ZEZZA, Marco Pino: l'opera completa, Napoli, 2003; G. PORZIO, Sollevando il velo del tempo. Dipinti del Cinque e Seicento, Napoli, 2015, pp. 8-15.

${ }^{4}$ Esta estampa fue catalogada por D. DEGRAZIA BOHLIN, Prints and Related Drawings by the Carracci Family: a Catalogue Raisonne, Washington, 1979, p. 506. Por su parte, B. NAVARRETE PRIETO, La pintura andaluza del siglo XVII y sus fuentes grabadas, Madrid, 1998, p. 272, lo cita como un modelo característico de los que utilizaban los pintores del siglo XVII, y apunta, a modo de ejemplo, que pudo servir de inspiración a Francisco Pacheco para una obra de 1637, destinada al coro bajo de la iglesia de San Alberto de Sicilia, en Sevilla.

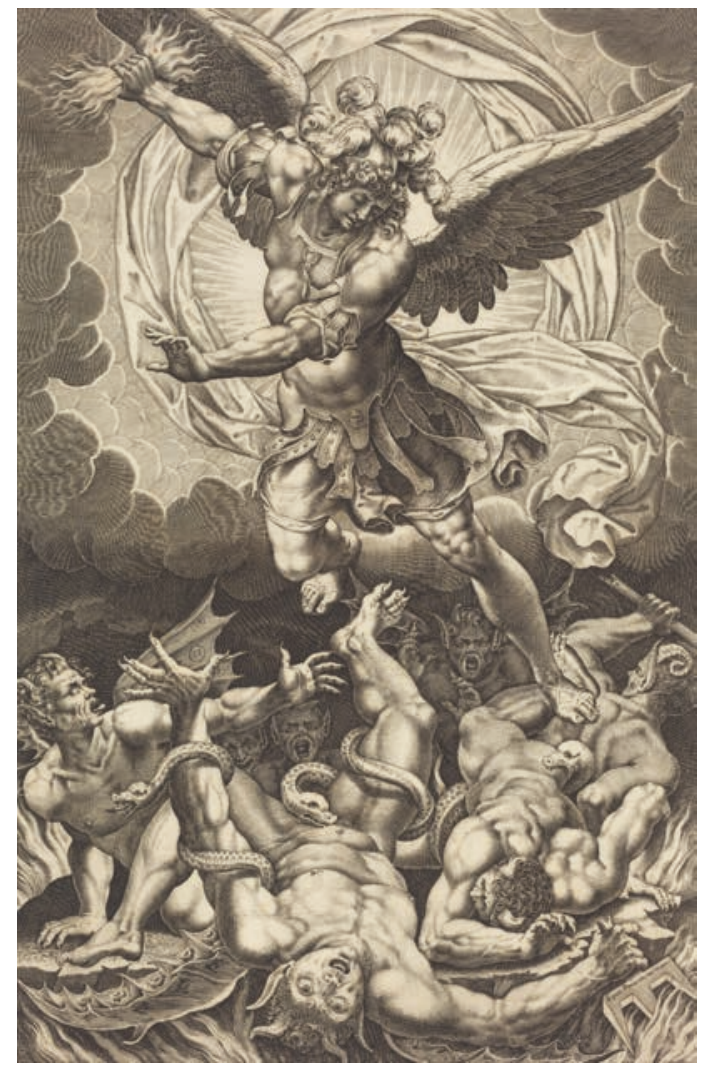

- Fig. 3. Philippe Thomassin. La caída de los ángeles rebeldes. 1618. Washington, National Gallery of Art, Andrew W. Mellon Fund, no. 1976.71.4.

dibuja una diagonal que conecta una de las alas del ángel con la espada. Los tonos claros de estos tres elementos se destacan sobre el fondo oscuro del cuadro y sobre la coraza azul del ángel, y marcan vehementemente esa diagonal. La línea diagonal se repite en la vaporosa banda blanca que cruza el pecho del arcángel y cae después, por debajo de la espada. Este recurso, unido a la línea curvilínea que acusa el resto del cuerpo, confiere gran dinamismo a la composición. Es destacable también la actitud ingrávida del santo, que parece descender desde el cielo para posarse sobre la tierra.

En relación al tratamiento de la luz, existen dos zonas diferenciadas con una intención claramente simbólica: una zona superior más luminosa, que ocupa dos tercios de la composición, donde campea la efigie del arcángel, y otra inferior más oscura, donde agoniza el monstruo. La iluminación 
procede del lado izquierdo del cuadro e incide con intensidad sobre el rostro de San Miguel, sutilmente girado hacia ese punto. Del mismo modo están iluminados su pecho, el brazo colocado en diagonal y parte de la cadera y las piernas, destacando una serie de elementos dorados de gran vivacidad en el cabello, el cuello, la empuñadura de la espada y las grebas.

El fondo está construido con tonalidades verdosas y pardas para proveer un ambiente caliginoso, que contrasta adecuadamente con los brillantes azules, rojos y encarnados de la figura principal, dibujada de forma segura y precisa, por cierto. La zona inferior está abocetada con colores terrosos, distinguiéndose la figura tumbada entre las rocas por medio de un complicado escorzo $\mathrm{y}$ tenues efectos de luz sobre el rostro, el pecho y uno de los hombros. La oscuridad dominante produce un efecto cavernoso, que identifica el inframundo donde el monstruo es condenado. La pincelada, en conjunto, está aplicada de manera muy diluida, casi sin empastes.

Iconográficamente, la imagen sigue la descripción del Libro del Apocalipsis, donde se narra la batalla de los ejércitos celestiales liderados por el arcángel San Miguel contra los ángeles rebeldes y el dragón, que representa al demonio ${ }^{5}$. La representación de esta escena ha mantenido una serie de constantes en la Historia del Arte Occidental a partir del siglo XIII, como son: que Miguel esté de pie, vestido como un caballero o un soldado romano, armado con elementos militares, alado como un ángel, y en una posición superior con respecto al demonio, a quien derrota en combate o humilla pisoteándole ${ }^{6}$. No

5 Apocalipsis, 12: 7-9 (edición de Reina-Valera, Madrid, 1995): "Entonces hubo una gran batalla en el cielo: Miguel y sus ángeles luchaban contra el dragón. Luchaban el dragón y sus ángeles, pero no prevalecieron, ni se halló ya lugar para ellos en el cielo. Y fue expulsado el gran dragón, la serpiente antigua, que se llama Diablo y Satanás, el cual engaña al mundo entero. Fue arrojado a la tierra y sus ángeles fueron arrojados con él."

${ }^{6}$ Iconográficamente, las alas constituyen el elemento obstante, también se han producido diversas variantes. En unos casos, el arcángel maneja una lanza, en otros una espada y en otros una espada llameante; en ocasiones se acompaña de otros atributos propios, como una balanza para el pesaje de las almas o unas cadenas con las que aferra al demonio; este último, por su parte, puede estar representado como uno o varios ángeles caídos, una figura monstruosa, oscura y vellosa pero de aspecto antropomorfo, un dragón o una serpiente ${ }^{7}$.

En cualquiera de los casos se trata de un tema especialmente dramático, que animó a los artistas del Barroco a explayar su creatividad a través de composiciones muy dinámicas. En el contexto artístico de la Italia del siglo XVII, del que bebe directamente nuestro cuadro, merece la pena citar algunas representaciones similares, como la de Andrea Vaccaro en la Galería Nacional de Praga (hacia 1650), y la ya mencionada de Luca Giordano, en la Gemäldegalerie de Berlín (1663). Sin embargo, las fuentes de inspiración recogidas en el cuadro de Alcalá provienen mayoritariamente del Cinquecento. El rostro y los cabellos rubios del arcángel nos parecen

fundamental para diferenciar a San Miguel respecto de otros santos guerreros como San Jorge. Antes del siglo XIII, en el Arte Bizantino, el Románico y la primera etapa del Gótico, el arcángel solía ir vestido con una túnica larga ceñida a la cintura, o una dalmática, que le hacía parecer un alto dignatario de la corte celestial. Durante la Baja Edad Media, se le añadió una cota de malla o una armadura y a veces, en particular en Francia, el emblema de cruzado. A partir del Renacimiento se prefirió la indumentaria de general romano, por el contexto de revivificación cultural de la Antigüedad Clásica. Véase J. FERRANDO ROIG, Iconografía de los Santos, Barcelona, 1950, p. 200; L. RÉAU, Iconografía del arte cristiano. Iconografía de la Biblia, Antiguo testamento. Tomo 1, vol. 1, Barcelona, 1996, pp. 65-76; R. GIORGI, Santos, Barcelona, 2004, pp. 270-274.

${ }^{7}$ Según E. MÂLE, El arte religioso de la Contrarreforma, Madrid, 2001, p. 228, en la Edad Media Satanás era frecuentemente representado "como un ser horrible que participaba de la naturaleza animal" pero, a partir del Renacimiento, su figura se volvió más humana y menos misteriosa, incluyendo sólo ciertos rasgos que recordaban su monstruosidad, como cuernos de carnero o alas membranosas. 
muy rafaelescos, mientras que otros detalles están directamente tomados del Juicio Final de Miguel Ángel (1536-1541). Por ejemplo, la anatomía y la posición de las piernas de San Miguel imita a las del gran Cristo de la Capilla Sixtina, su brazo izquierdo apuntando hacia atrás es similar al del personaje central del grupo de ángeles trompeteros situado debajo de aquél, y la corpulenta figura de Satán, bocarriba y con las piernas cruzadas, es similar a un demonio colgado de una nube, a la derecha del grupo anterior.

El culto a San Miguel fue especialmente importante en Italia, debido entre otras razones a la devoción popular desarrollada a partir de su aparición milagrosa en el Monte Gargano, en la región de Apulia. Después del Concilio de Trento, su figura adquirió un impulso renovado y también una nueva dimensión. Para el movimiento contrarreformista, y en particular para algunas órdenes religiosas como los jesuitas, el santo guerrero se convirtió en una elocuente personificación de la Iglesia Militante triunfando sobre la herejía y el mal en el mundo. Al igual que San Miguel sometió y desterró a los ángeles rebeldes, los católicos luchaban contra los herejes protestantes ${ }^{8}$.

El cuadro que publicamos en estas páginas sigue en cierta medida los presupuestos formales de la pintura contrarreformista, por su elevado carácter emblemático. La victoria del catolicismo sobre las fuerzas del mal está representada por medio de una iconografía clara y directa, sin figuras o efectos innecesarios que distraigan la atención. A ello contribuye, sin duda, el lenguaje plástico utilizado por el artista que, aun siendo barroco, se expresa mediante un dibujo y un colorido marcadamente clasicistas.

${ }^{8}$ L. RÉAU, Op. cit., p. 71, menciona un grabado del flamenco Jan Galle titulado Diaboli Haereticique Lapsus simillimus que "representa a san Miguel arrojando a Lucifer desde lo alto del cielo y paralelamente a la Iglesia precipitando a Lutero a las llamas del Infierno". Sobre este tipo de connotaciones véase también $\mathrm{E}$. MÂLE, Op. cit., pp. 279-282.
En realidad, toda la pintura italiana del siglo XVII vivió en medio de esta contradicción. En los primeros años tuvo lugar una vehemente búsqueda del naturalismo, derivando con frecuencia hacia un tenebrismo descarnado, de la mano de Caravaggio y Ribera. Le siguió una vuelta al clasicismo liderada por las escuelas romana y boloñesa, e influenciada por los grandes artistas del Cinquecento, que recuperó la importancia del dibujo, aclaró el color y simplificó las composiciones, excluyendo elementos superfluos. Entre ambas corrientes acabó desarrollándose una tercera vía netamente barroca, en la que pintores como Pietro da Cortona, Carlo Maratti y Luca Giordano lograron una eficaz síntesis de ciertos principios clasicistas complementada con el brillante colorido de la tradición veneciana, la potencia figurativa de Miguel Ángel y el ilusionismo óptico de los grandes ciclos decorativos ${ }^{9}$. En medio de esta controversia desarrolló su trayectoria artística Giacomo Farelli, el autor que puso su firma en el cuadro de los maristas.

\section{APROXIMACIÓN A LA FIGURA DE GIACOMO FARELLI}

Hasta hace poco, Farelli era bastante desconocido para la generalidad de la Historia del Arte, hasta el punto de no aparecer ni siquiera citado en muchas obras de referencia sobre la pintura italiana del Barroco; en España ha pasado casi por completo desapercibido $^{10}$. En los últimos años su figura

\footnotetext{
${ }^{9}$ Véase entre otros M. GREGORI y E. SCHLEIER, $L a$ pittura in Italia. Il Seicento, Milano, 1989; R. WITTKOWER, Arte y arquitectura en Italia, 1600-1750, Madrid, 1992. G. PACCIAROTTI, La pintura barroca en Italia, Madrid, 2000. Sobre el debate artístico desarrollado durante la primera mitad del siglo XVII, focalizado en la figura de Domenichino, véase E. CROPPER, The Domenichino affair, New Haven, 2005. Para el caso concreto de Nápoles, donde se sitúa mayormente la obra de Giacomo Farelli, véase N. SPINOSA, Pittura del Seicento a Napoli, da Mattia Preti a Luca Giordano, Napoli, 2011.

10 Por ejemplo, no aparece mencionado en la reciente exposición comisariada por N. SPINOSA y A. E. PÉREZ SÁNCHEZ (coords.), Seicento Napoletano. Del Naturalismo al Barroco, Madrid, 2008.
} 
y su obra están empezando a ser valorados en el mercado internacional del arte, hasta el extremo de que han salido a la venta numerosos cuadros destinados al coleccionismo privado $^{11}$. Como resultado de ello, su catálogo ha aumentado considerablemente, lo que ha dado lugar a la publicación de una cierta cantidad de artículos, a una monografía en italiano y a una tesis doctoral ${ }^{12}$.

Las primeras fuentes históricas que hicieron referencia a Giacomo Farelli fueron los tratados de Bernardo De Dominici en el siglo XVIII y Camillo Minieri-Riccio en el XIX. Ambos aportaron datos relevantes sobre su biografía y localizaron algunas de sus mejores pinturas en varias iglesias napolitanas, valorando positivamente su figura ${ }^{13}$. Una revisión contrastada de esos datos su-

11 Véase a modo de ejemplo ARTNET, “Giacomo Farelli (Italian, 1624-1706). Auction results" (en línea), consultado el 25 de junio de 2017. URL: http://www. artnet.com/artists/giacomo-farelli/past-auction-results

${ }^{12}$ Véase I. GALLICHI SCHWENN, "Note su Giacomo Farelli pittore napoletano del seicento”, Partenope, vol. I, 1961, pp. 200-213; M. A. PAVONE, "The master of Christ and the adulteress, a precedent for the early work of Farelli", Prospettiva. Rivista di Storia dell Arte Antica e Moderna, $\mathrm{n}^{\mathbf{0}}$ 57-60, 1990, pp. 265-272; L. RAUCCI, "Il cavalier Giacomo Farelli, un pittore tra Napoli e l'Abruzzo", Napoli nobilissima: rivista di arti, filologia e storia, $\mathrm{n}^{-}$3-4, 2004, pp. 93-104. La monografía es de A. DELLA RAGIONE, Giacomo Farelli Opera Completa, Napoli, 2011; y L. RAUCCI, Giacomo Farelli pittore, Tesis doctoral defendida en la Università degli studi di Napoli, 2003.

${ }^{13}$ B. DE DOMINICI, Vite de' pittori, scultoried architett $i$ napoletani, Napoli, 1743, edizione commentata a cura di F. Sricchia Santoro e A. Zezza, vol. III, pp. 867-883, Nápoles, 2008. C. MINIERI-RICCIO, Memorie storiche degli scrittori nati nel Regno di Napoli, Napoli, 1844, p. 123. Ambos cometen un error sobre el lugar y la fecha de nacimiento del pintor, que sitúan en Nápoles en 1624. Por su parte, U. THIEME, y F. BECKER, Allgemeines Künstler-Lexikon. Die Bildenden Künstler aller Zeiten und Völker, edición de K. G. Saur, München, 2003, vol. 37, p. 24 , repiten el año de 1624 pero trasladan el nacimiento a Roma. Finalmente, A. DELFINO, "Documenti inediti sui pittori del '600", en Ricerche sul '600 napoletano, Milano, 1988, p. 58, descubrió nuevos documentos históricos que establecieron como fecha definitiva 1629 , aunque sobre la patria del artista continúa habiendo debate. giere que Farelli nació en Roma, no en Nápoles, en 1629. Su llegada a la ciudad partenopea debe cifrarse antes de 1644, cuando entra como alumno en el taller de Andrea Vaccaro. Allí se ejercitó en el diseño, copiando numerosas estampas y estudiando anatomía hasta adquirir la capacitación artística necesaria para acometer sus primeras obras, fechadas a partir de 1651. La mayor parte de su producción artística se desarrolló luego en la zona de Nápoles, ciudad en la que murió y fue enterrado, en el año 1706, en la iglesia de Santa Maria dei Sette Dolori ${ }^{14}$.

La obra de Giacomo Farelli puede clasificarse atendiendo a diversos criterios, como la técnica pictórica, la temática o la localización geográfica. En relación al primer criterio, abarca tanto dibujos como pinturas al óleo y decoraciones al fresco, que en conjunto casi alcanzan el centenar. Quizás lo menos conocido sean sus dibujos, pero merecen citarse tres ejemplares magníficos, trazados con lápiz y tinta, que se conservan en la Morgan Library de Nueva York ${ }^{15}$. En

${ }^{14}$ M. A. PAVONE, "Farelli, Giacomo”, en Dizionario Biografico degli Italiani (en línea), vol. 44, 1994, consultado el 20 de marzo de 2017. URL: http://www.treccani.it/ enciclopedia/giacomo-farelli_(Dizionario_Biografico)/. En cambio, U. THIEME y F. BECKER, Op. cit., p. 24, siguiendo a otros autores, dan el año 1701 como la fecha del fallecimiento de Farelli.

${ }^{15}$ Estos dibujos pueden admirarse en The Morgan Library \& Museum, "Giacomo Farelli" (en línea), consultado el 20 de junio de 2017. URL: http://www. themorgan.org/search/site/farelli. Otro ejemplo accesible en internet es el que se conserva en el Museo Nacional de Diseño Copper-Hewitt de Nueva York, catalogado como una Apoteosis de una Santa realizado con lápiz, tinta y acuarela azul; véase en Google Art Project, "Farelli, Giacomo - Apotheosis of a Female Saint" (en línea), consultado el 25 de junio de 2017. URL: https://commons.wikimedia.org/wiki/File:Farelli,_ Giacomo_-_Apotheosis_of_a_Female_Saint_-_Google_ Art_Project.jpg. M. A. PAVONE, Farelli..., menciona otro dibujo firmado por Farelli en el Museo di San Martino de Nápoles. Finalmente, el Fitzwilliam de Cambridge guarda otro dibujo de Dios Padre sosteniendo a Cristo muerto adorado por un grupo de santos, que se atribuye a Farelli; véase en The Fitzwilliam Museum, "God the Father, holding the dead Christ, in Glory, adored by Angels and St. John the Evangelist, St. Luke, St. Andrew, St. Mark? (or Jerome?), St. Ignatius Loyola 
relación con la temática, Farelli es autor de obras mayoritariamente religiosas, aunque también pintó asuntos mitológicos e históricos. Entre estos últimos destacan sobremanera los frescos de la Sala delle Baleari en el Palazzo Comunale de Pisa (1693), en los que representó con gran espectacularidad la conquista de las Islas Baleares por parte de la República de Pisa ${ }^{16}$.

En cuanto a la localización geográfica de las obras, se extiende por varias regiones de la Italia central y meridional, incluyendo Campania, Abruzzo y Toscana. Una de las razones de esta dispersión es su estatus como Caballero de la Orden de Malta, que llevó a Farelli a desempeñar cargos políticos y administrativos al servicio de la nobleza, como el gobierno de la ciudad de L'Aquila ${ }^{17}$. Se han identificado pinturas suyas en Atri, Chieti, Cermignano, Sulmona y L'Aquila, en la región de Abruzzo, además de otras en Melfi, Giulianova, Capri y numerosos cuadros de altar en el área metropolitana de Nápoles $^{18}$.

and an unidentified male saint" (en línea), consultado el 25 de junio de 2017. URL: http://webapps.fitzmuseum. cam.ac.uk/explorer/index.php?oid $=6890$

${ }^{16}$ R. MONTERA, "Gli affreschi di Giacomo Farelli nella Sala delle Baleari di Palazzo Gambacorti", Rassegna del Comuni di Pisa, 1972, nº 3-4, pp. 18-22, nº 5-6, pp. 2226, no 7-9, pp. 35-39; A. AMBROSINI, La decorazione ad affresco nel palazzo del Comune di Pisa, in Palazzo Gambacorti a Pisa. Un cantiere in restauro, Venezia, 1998; S. PIANE, "Restauro Sala delle Baleari: presentato ieri alla stampa Il Trionfo delle Baleari di Giacomo Farelli" (en línea), consultado el 25 de junio de 2017. URL: http://cultura.comune.pisa.it/?p=1928.

${ }^{17}$ G. C. ASCIONE, "L'attivita del pittore Giacomo Farelli in Abruzzo", Atti del VI Convegno: Gli Acquaviva d'Aragona duchi di Atri e conti di S. Flaviano, Teramo, 1985, pp. 149-158; M. VACCARO, "Alcune tele inedite di Giacomo Farelli in Abruzzo", Bollettino d'arte, no 98, 17, 2013, pp. 95-104.

${ }^{18}$ N. SPINOSA, La pittura napoletana del '600, Napoli, 1984, fig. 332-337; G. CAUTELA, L. DI MAURO, R. RUOTOLO y N. SPINOSA, Napoli sacra. Guida alle chiese della città, Napoli, 1993-1997; R. PINTO, La pittura napoletana, Napoli, 1998, p. 274; E. PERSICO ROLANDO, “La decorazione affrescata di alcuni sottarchi nella Chiesa del Gesù Nuovo a Napoli. Aggiunte a Giacomo Farelli", Campania Sacra, XXXIII,
Estilísticamente, Giacomo Farelli evolucionó desde un naturalismo tenebrista, que nunca abandonó por completo, hacia un clasicismo construido mediante un dibujo académico y un cromatismo suave, sin duda aprendidos de su maestro Andrea Vaccaro. Estuvo influido en sus inicios por varios artistas activos en Nápoles a finales de la década de 1640, como Cesare Fracanzano y Massimo Stanzione. Posteriormente trató de emular la obra de Guido Reni y Domenichino, y en ocasiones colaboró con Francesco di Maria ${ }^{19}$. A partir de 1660, su progresiva destreza como pintor le fue acercando a un barroquismo de colores más claros y brillantes, con figuras más grandes, y sutiles efectos luminosos inspirados por Giovanni Lanfranco, Mattia Preti y, sobre todo, Luca Giordano. Con este último compitió en la iglesia de Santa Brígida de Nápoles, en 1655, al realizar cada artista una pintura de altar: Giordano, el Milagro de San Nicolás, y Farelli, la Aparición de Cristo y María a Santa Brígida ${ }^{20}$. La obra de ambos pintores coincidiría más tarde en la Capilla del Tesoro de la Catedral de San Genaro, donde el Cavaliere Farelli pintó al fresco los lunetos y la bóveda de la antesala de la sacristía, a partir de $1664^{21}$.

$\mathrm{n}^{\mathrm{o}}$ 1-2, 2002, pp. 230-231; L. RAUCCI, “Giacomo Farelli in Abruzzo", en R. TORLONTANO, Abruzzo. Il barocco negato: aspetti dell'arte del Seicento e del Settecento, Roma, 2010, pp. 166-171; R. LATTUADA, “Farelli tra Abruzzo e Napoli: nuove opere e note sullo sviluppo stistico", en R. TORLONTANO, Op. cit., pp. 187-196.

${ }^{19}$ Véase M. GREGORI y E. SCHLEIER, Op. cit.; M. A. PAVONE, Farelli...; J. TURNER, The Dictionary of Art, New York, 1996, vol. 10, p. 803; y A. ZEZZA, “Une histoire de l'art sans héros? Études récentes sur la peinture napolitaine du XVIIe siècle", Perspective, actualité en histoire de l'art, 2011, pp. 435-459 (en línea), consultado el 25 de junio de 2017. URL: https:// perspective.revues.org/973

${ }^{20}$ R. RUOTOLO y A. NIEGO, S. Brigida, Napoli, 1978, pp. 37-38.

${ }^{21}$ C. CATELLO y E. CATELLO, La cappella del tesoro di San Genaro, Napoli, 1977, pp. 49-50; F. STRAZZULLO, La Real Cappella del tesoro di San Genaro: documenti inediti, Napoli, 1978, pp. 68-69; N. SPINOSA, "La pittura del Seicento nell'Italia meridionale", en La pittura in Italia. Il Seicento, vol. I, Milano, 1989; M. A. PAVONE, Farelli... puntualiza el tema de estos frescos, que tratan escenas 


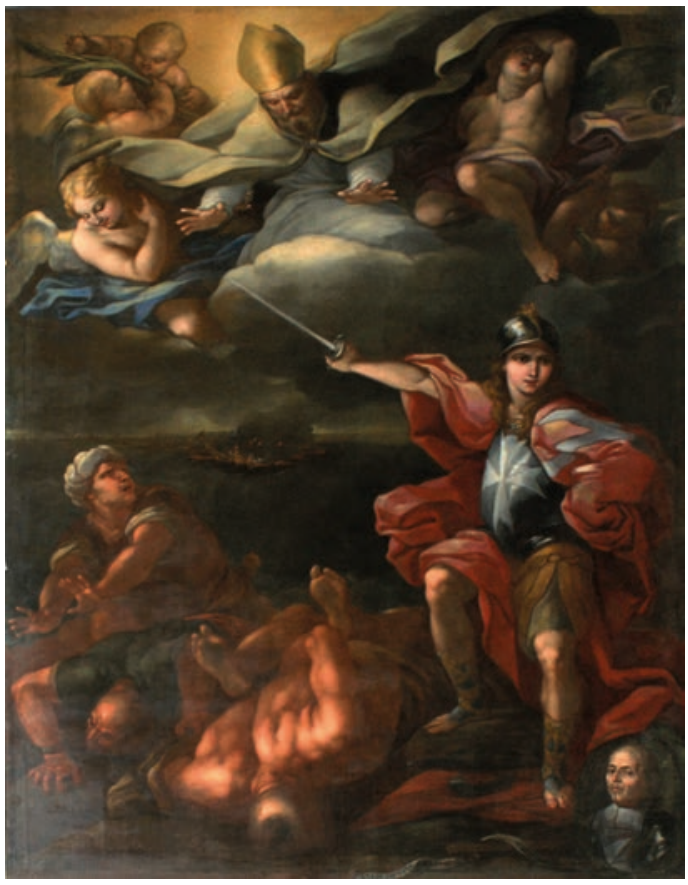

- Fig. 4. Giacomo Farelli. San Rufo combatiendo contra los turcos. Hacia 1680. Nápoles, Iglesia de San Giuseppe dei Ruffi. Foto de Dante Caporali.

Por consiguiente, su trayectoria se mueve entre el tenebrismo y el barroquismo, con frecuentes alusiones a la tradición clásica del Cinquecento, y en particular a la obra de Miguel Ángel. El tratadista De Dominici señalaba como elemento destacado en sus obras la presencia de cuerpos atléticos y escorzos audaces, así como el empleo de un finísimo azul ultramarino ${ }^{22}$, mientras que la principal monografía dedicada al artista le atribuye "lunghe e proficue meditazioni romane a cospetto della Sistina"23. Otra posibilidad es que Farelli conociera la obra de Buonarroti a través de

de la vida de Santa Ana en los lunetos y la Inmaculada en la bóveda, y fueron firmadas como "Farello".

${ }^{22}$ B. DE DOMINICI, Op. cit, pp. 868-869.

${ }^{23}$ A. DELLA RAGIONE, Op. cit., p. 2. Los motivos miguelangelescos reinterpretados por Farelli son también apreciables en obras como la decoración mural del Santuario di Santa Maria della Croce, en Roio (1667). Véase al respecto O. LUCIANI, "Il Ciclo pittorico di Giacomo Farrelli nel Santuario di Maria SS della Croce di Roio esprime aspetti devozionali mariani del suo tempo" (en línea), consultado el 25 de junio de 2017. URL: http://oresteluciani.eu/GiacomoFarrelli.pdf la interpretación que hizo de ella Marco Pino en sus obras napolitanas, que desde luego se distinguen por la introducción de figuras sinuosas y escorzos, así como por el estudio anatómico de los cuerpos. Como ejemplo de ello pueden recordarse la Degollación de Juan el Bautista (hacia 1564) y la Adoración de los Magos (hacia 1568) del Museo de Capodimonte. Esta fuente de inspiración es desde luego más directa, puesto que Pino dejó testimonios de su arte en muchos de los escenarios por los que se movió el Cavaliere, como en la iglesia de Sant'Angelo a Nilo, donde se encuentra el grandioso cuadro de San Michele, ya mencionado.

Todo lo expuesto se muestra en el cuadro de Alcalá de Henares: la zona inferior mantiene el tenebrismo característico de principios de la centuria, la potente figura del arcángel tiene detalles muy miguelangelescos, el dibujo y el brillante colorido se inspiran en el clasicismo de la escuela romana $\mathrm{y}$, tanto el tratamiento de la luz en la zona superior como el dinamismo de la composición son propios del último Barroco, en particular de Giordano.

Por otra parte, el cuadro tiene fuertes concomitancias con otras dos obras napolitanas producidas por Giacomo Farelli en su etapa de madurez. La primera de ellas, realizada en la década de 1680, está en la iglesia de San Giuseppe dei Ruffi en Nápoles y encarna a San Rufo combatiendo contra los tur$\cos$ (Fig. 4). La figura de este santo guerrero resulta muy similar a la del San Miguel del cuadro de los maristas, por el azul ultramarino de su coraza, el manto rojo ondeando al viento, la forma del yelmo y las grebas tachonadas de oro que protegen sus piernas. La poderosa anatomía del sarraceno muerto en primer término recuerda también al demonio de la pintura de Alcalá, mientras que el tratamiento de la luz y el color del fondo son parecidos en ambos casos.

La segunda obra relacionada está en la iglesia de San Giuseppe a Chiaia y representa La muerte de San José. Según un documento de pago descubierto recientemente, está 
fechada en $1690^{24}$. En su extremo izquierdo aparece la figura escorzada del arcángel San Miguel sometiendo al demonio, con el mismo detalle del brazo derecho cruzado sobre el cuerpo, para agarrar la espada, y la misma coraza azul envuelta por un manto rojo brillante. La figura está inundada por una luz resplandeciente y mantiene una actitud serena y grácil, en el marco de una composición extremadamente barroca, en la que se aprecia una clara asimilación de la maniera giordanesca (Fig. 5).

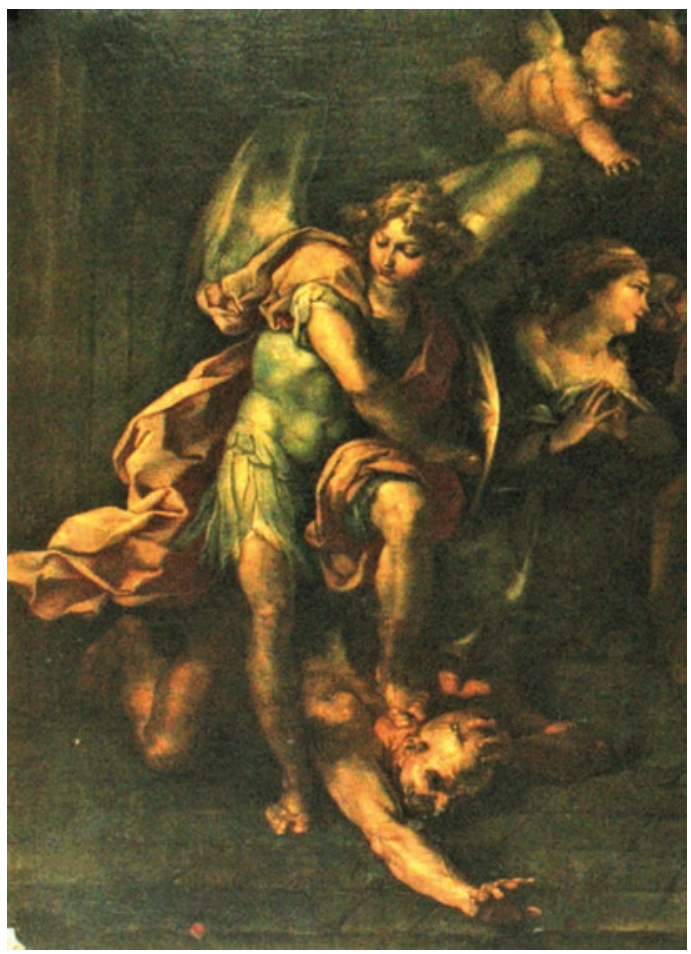

- Fig. 5. Giacomo Farelli. Muerte de San José (detalle). 1690. Nápoles. Iglesia de San Giuseppe a Chiaia. Foto de Dante Caporali.

Podemos añadir una última referencia en los frescos del Palazzo Comunale de Pisa, que fueron realizados en 1693, es decir, en el mismo período de madurez artística de Farelli. La composición dedicada a La derrota de los Sarracenos (Fig. 6) repite numerosos detalles miguelangelescos en la posición de los cuerpos y en la potente musculatura de los desnudos, que son similares a los ya co-

\footnotetext{
${ }^{24}$ A. DELLA RAGIONE, Op. cit., p. 13.
}

mentados en la figura de Satán del cuadro de Alcalá. En particular, el mahometano tendido bocarriba en la esquina inferior derecha, dobla de manera forzada la rodilla en una postura muy parecida.

Todas estas coincidencias hacen suponer que el lienzo de los maristas pueda situarse en el mismo contexto histórico-artístico y, por consiguiente, proponemos como fecha probable de ejecución en torno al año 1690. Más complicado es determinar el sitio y el destino inicial para el que fue realizado, pues no tenemos ninguna noticia al respecto.

\section{VICISITUDES DEL CUADRO HASTA LA ACTUALIDAD}

Nuestra primera hipótesis nos lleva a pensar en un origen napolitano del cuadro, que finalmente acabó en España como resultado de la incesante incorporación de pinturas italianas a las colecciones particulares de la nobleza de aquella época. En el siglo XVII fue habitual que el arte italiano se sobrevalorase por encima del español, aunque también es cierto que la Escuela Napolitana tuvo una estimación y una presencia menos destacada en las colecciones, en comparación con los grandes artistas del Renacimiento y las obras de las escuelas romana y veneciana. Pero la fama de Luca Giordano ejerció una fascinación tal, que cualquier cosa salida de su círculo resultó especialmente atractiva para los compradores, incluso aunque fueran simples imitaciones, falsificaciones o producciones realizadas por seguidores de menor valía. Téngase en cuenta que en los últimos años del siglo XVII vino a trabajar a España un nutrido grupo de pintores italianos que, junto con otros artistas españoles, contribuyeron sobremanera a la difusión de los modelos de Luca Giordano ${ }^{25}$. Además de lo expuesto, durante todo el período barroco se desarrolló un prolífico comercio artístico

${ }^{25}$ Véase Luca Giordano y España, Catálogo de la exposición, Madrid, 2002 y M. HERMOSO CUESTA, Lucas Jordán y la Corte de Madrid, una década prodigiosa (1692-1702), Zaragoza, 2008, pp. 251-265. 


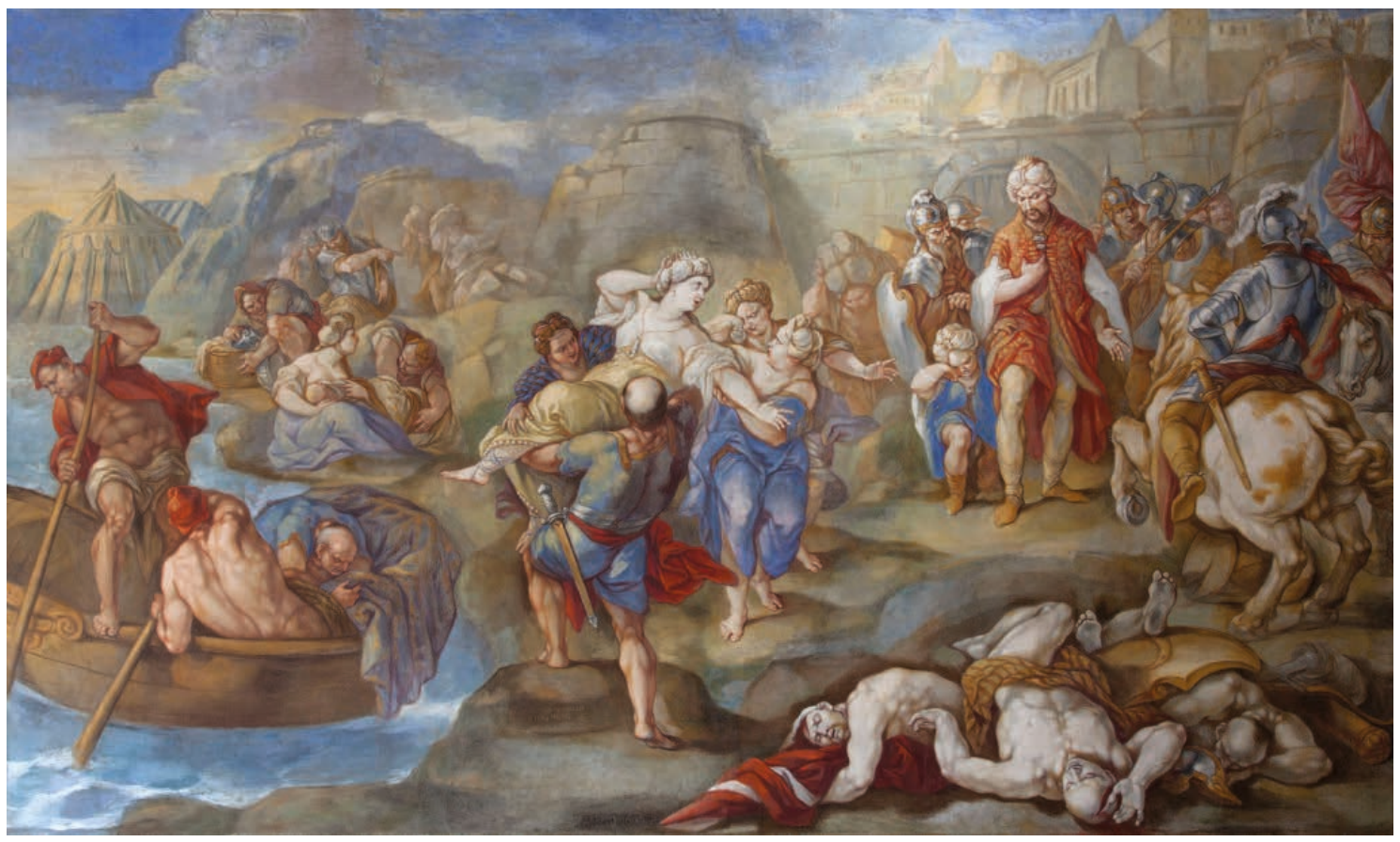

- Fig. 6. Giacomo Farelli. La derrota de los Sarracenos. 1693. Palazzo Comunale de Pisa, Sala delle Baleari. Foto de Comune di Pisa.

con Nápoles ${ }^{26}$, que podría justificar con facilidad la adquisición del cuadro que nos concierne y su posterior traslado a España.

A este respecto, hay que añadir la existencia de algunas referencias documentales que sitúan obras de nuestro artista en Madrid. La primera proviene de un inventario del Alcázar, fechado en 1694, que recoge dos Alegorías del Tiempo del caballero Farelli ${ }^{27}$. La

26 R. RUOTOLO, Mercanti collezionisti a Napoli: Gaspare Roomer e $i$ Van den Eynden, Meta di Sorrento, 1982, pp. 23, 33 y 36; M. J. MUÑOZ GONZÁLEZ, El mercado español de pinturas en el siglo XVII, Madrid, 2008, pp. 138-150 y 216-231.

${ }^{27}$ A. E. PEREZ SANCHEZ, Pintura italiana del siglo XVII en España, Madrid, 1965, p. 392. Después de una breve introducción biográfica que señala su formación con Vaccaro y la influencia recibida de Giordano, se cita la siguiente descripción extractada del susodicho inventario de 1694: “Una pintura en lienzo de una fábula que significa el tiempo, de más de dos varas de alto y dos y media de ancho, de mano del caballero Farelli". Más adelante: "Otro de dos varas y media de ancho y dos de alto, sin marco, maltratado, de un geroglífico de una mujer y el tiempo, de mano del caballero Farelli". Según Pérez Sánchez, la primera obra estaba en el obrador de los pintores de cámara; la segunda se salvó del incendio de 1734 porque aparece documentada en segunda ha sido recientemente publicada por Burke y Cherry, quienes localizaron "un quadro che rappresenta il tiempo che sucopre la verità di mano del Cavalier Farelli" en la extensa colección de Gaspar de Haro y Guzmán, Marqués del Carpio y de Eliche, según fue catalogada en Roma en el año $1682^{28}$. Otra referencia, más problemática, es de Rosselli, que en 1697 elogió la virtud de Farelli "nel celebre palagio dello Scoriale" 29 . Este último dato debe ser tratado con extrema cautela pues no está refrendado por otras fuentes distintas de las napolitanas, y en realidad no existe ninguna obra de nuestro artista en El

Palacio en 1747, aunque luego se pierde su rastro en los inventarios. Las dos están consideradas como obras perdidas o no identificadas.

${ }^{28}$ M. B. BURKE y P. CHERRY, Collections of Paintings in Madrid, 1601-1755, Los Angeles, 1997, Part 1, p. 730. La descripción concuerda con una de las imágenes recogidas en el inventario del Alcázar de Madrid del año 1694 .

29 G. ROSELLI, Premessa alla II edizione, en P. SARNELLI, Guida de' forestieri, curiosi di vedere, e di riconoscere le cose più memorabili di Pozzuoli, Baja, Cuma, Miseno, Gaeta, ed altri luoghi circonvicini, Napoli, 1697, citado por A. DELLA RAGIONE, Op. cit., pp. 21-22. 
Escorial $^{30}$. Por último, Burke y Cherry han hallado otras cinco pinturas de Farelli en un inventario de la colección del Marqués del Puerto, redactado en Madrid en $1753^{31}$. Ninguna de estas obras parece tener relación con la que estudiamos en este artículo, pero nos permite constatar que Giacomo Farelli adquirió un cierto grado de aceptación en el mundo del coleccionismo y el mercado del arte en la España de los siglos XVII y XVIII.

En cualquier caso, no tenemos datos concretos que expliquen la llegada a la Península Ibérica del cuadro de San Miguel Arcángel venciendo al demonio. Su paradero es completamente desconocido hasta que, a principios del siglo $X X$, se localiza en el colegio de las monjas de la Congregación de Jesús, vulgo "Madres Irlandesas", en la localidad vizcaína de Zalla. Esta institución fue fundada en 1904 como un internado para niñas de la alta burguesía y la aristocracia ${ }^{32}$.

${ }^{30}$ Farelli no aparece mencionado por V. POLERÓ, Catálogo de los cuadros del Real Monasterio de San Lorenzo, llamado del Escorial, Madrid, 1857; ni por E. J. ZARCOBACAS, El monasterio de Sn. Lorenzo el Real de El Escorial, y la Casita del Príncipe, Madrid, 1926. Tampoco hay referencias al respecto en F. J. CAMPOS Y FERNÁNDEZ DE SEVILLA (coord.), Actas del Simposio El Monasterio de El Escorial y la Pintura, El Escorial, 2001. En el transcurso de nuestra investigación, los técnicos conservadores de Patrimonio Nacional han confirmado la ausencia de obras de Farelli en El Escorial.

31 M. B. BURKE y P. CHERRY, Op. cit., Part 1, pp. 1061-1064. Los temas de estos cuadros, según el inventario reseñado, son Lot y sus hijas, La expulsión de Adán y Eva del Paraíso, Caín y Abel, y dos imágenes de la reina Cleopatra y de Lucrecia. El Marqués del Puerto, cuyo nombre era Joaquín Ignacio de Barnachea, fue también Vizconde de Enzinar y embajador en Suecia durante el gobierno de Felipe V. Posteriormente, Fernando VI le nombró embajador en Holanda, donde falleció el 10 de marzo de 1753. Su colección de arte fue tasada por el pintor Andrés de la Calleja y vendida un año después.

${ }^{32}$ La fundación del Colegio de las Irlandesas de Zalla debe entenderse dentro de un contexto muy particular, a principios del siglo XX, cuando se amplió de forma notable la presencia de congregaciones de frailes y monjas en el País Vasco, como consecuencia de la legislación laicista que aumentó las expulsiones de religiosos de Francia. Véase J. LOUZAO VILLAR, Soldados de la fe o amantes del progreso: Catolicismo y
El edificio colegial, con su capilla, se construyó en 1918 precisamente bajo la advocación de San Miguel ${ }^{33}$. Entre las obras de arte con que fue adornado destacaba el cuadro que nos ocupa, que representa al santo patrón del colegio y también de la localidad de Za1la. Según han confirmado testigos oculares, el cuadro estaba expuesto en el corredor de acceso a la capilla.

Cómo llegó la pintura de Farelli al colegio de Zalla es una incógnita. Se nos plantean dos posibilidades: que viniera con las monjas al inicio del proceso fundacional de 1904, o que se trate de una adquisición posterior. No tenemos datos sobre ninguno de los dos supuestos, pero nos inclinamos por la segunda hipótesis. La Congregación de Jesús o Instituto de la Bienaventurada Virgen María es una orden religiosa de larga tradición, cuyo origen se remonta al año 1609. Durante los siglos XVII y XVIII experimentó un cierto desarrollo en los Países Bajos, Alemania e Italia, aunque hubo de enfrentarse a la oposición de la curia vaticana, que no concebía una congregación femenina que se dedicara a actividades socio-educativas y no adoptase un estilo de vida estrictamente contemplativo, en clausura. Denominadas despectivamente como "Jesuitinas" o "Jesuitesas", por su similitud con el ideario de la Compañía de Jesús, las monjas no consiguieron ser oficializadas por la jerarquía de la Iglesia Católica hasta 1877, fecha en que también fue rehabilitada la figura de su fundadora, la inglesa Mary Ward ${ }^{34}$. Teniendo en cuenta estas

modernidad en Vizcaya (1890-1923), Logroño, 2011, pp. 94-104. También, J. INTXAUSTI (ed.), Actas del Primer Congreso de Historia de las familias e Institutos Religiosos en el País Vasco y Navarra, Arantzazu, 2002. Un análisis particular, centrado en el caso de Guipúzcoa, puede leerse en M. OSTOLAZA ESNAL, Entre religión y modernidad: los colegios de las Congregaciones Religiosas en la construcción de la sociedad guipuzcoana contemporánea, 1876-1931, Leioa, 2000.

${ }^{33}$ M. A. ROYO RUIZ, Zalla. Estudio histórico-artístico, Bilbao, 1997, p. 178.

34 A. YETANO LAGUNO, "Las Congregaciones religiosas femeninas en el XIX. El tema de la obtención de su nuevo estatuto jurídico canónico y su interés 
dificultades, se nos antoja improbable pensar que esta congregación llegase a atesorar obras de arte de cierta calidad a principios del siglo XX. En cambio, el colegio de Zalla acabó convirtiéndose con posterioridad en uno de los establecimientos educativos más elitistas del País Vasco, y no sería de extrañar que las monjas hubieran recibido donaciones de importantes mecenas y familiares de alumnas. Si seguimos esta línea de pensamiento, el cuadro habría pasado por diversos propietarios en España, desde finales del siglo XVII o principios del XVIII, hasta que finalmente fue regalado a las Madres Irlandesas, en fecha indeterminada.

A lo largo del siglo XX el colegio de Zalla fue evolucionando hasta transformarse en un centro de alumnado mixto y abierto a todas las clases sociales, que logró un fuerte arraigo en el municipio. Pero en 1993 las monjas decidieron ceder la propiedad del colegio y todo su patrimonio al Instituto de los Hermanos Maristas, que se hicieron cargo de su mantenimiento y de la gestión de la actividad docente. En el transcurso de una reforma, el cuadro de San Miguel Arcángel fue retirado de su ubicación y abandonado con poco cuidado en un desván. Los Maristas nunca se han distinguido por coleccionar obras de arte, ya que su vocación se ha dirigido principalmente a la educación de los niños y jóvenes desfavorecidos. Por otra parte, las virtudes de humildad, sencillez y modestia fueron consideradas por su fundador, San Marcelino Champagnat, cualidades

historiográfico", Spagna Contemporanea, nº 36, 2009, p. 20, señala la Constitución Quamvis Iusto, promulgada por el Papa Benedicto XIV en 1749, como una primera aceptación de la existencia de esta congregación, que había sido suprimida por el Papa Urbano VIII en 1631. Este documento aprobó un conjunto de normas muy innovadoras para una orden femenina en aquella época (votos simples, ausencia de clausura, estructuración centralizada y jerárquica, y una superiora general) que se convertirían en modelo para otras congregaciones posteriores. La Constitución apostólica Conditae a Christo, promulgada por el Papa León XIII en 1900, regularizó en este sentido las normas de las nuevas congregaciones religiosas femeninas surgidas a lo largo del siglo XIX especialmente significativas del carisma de la congregación. A pesar de todo ello, el Superior de la Provincia Ibérica Marista consideró la necesidad de impedir que la pintura sufriera un mayor deterioro y poco después aceptó su traslado a la casa principal de Alcalá de Henares, donde se encuentra a día de hoy ${ }^{35}$.

Con el fin de garantizar su adecuada conservación y exhibición pública, se iniciaron gestiones para la necesaria restauración del cuadro. El diagnóstico del estado de conservación de la pintura, el bastidor y el marco sacó a la luz importantes patologías, sobre todo en la parte superior. La tela estaba destensada por falta de fijación y presentaba problemas de adherencia de la capa pictórica, con varias pérdidas, craqueladuras, zonas abrasadas y numerosos orificios, además de un oscurecimiento general de la película protectora. Los bordes de la misma se encontraban dañados debido a las marcas de un bastidor de tamaño diferente, que fue añadido con posterioridad, y a los puntos de oxidación ocasionados por los clavos de sujeción. También se detectaron intervenciones anteriores sin documentar, como el estucado de algunos agujeros y el cosido de dos rotos más recientes, así como diversos repintes con óleo. Por último, se comprobó que el lienzo original había sido re-entelado con tres piezas, unidas por una costura vertical en el centro y otra transversal en la zona inferior. El bastidor, por su parte, había sido atacado por xilófagos, al igual que el marco del cuadro, que tenía desprendimientos en las molduras doradas y pérdidas de volumen por fracturas.

La restauración fue realizada en la ciudad de Alcalá de Henares, durante el primer semestre de 2014, y se limitó a una labor de limpieza, eliminación de barnices y consolidación de la capa pictórica, respetándose las

${ }_{35}$ Mi más sincero agradecimiento a José María Amigo Ortega (F.M.S.), por haber recopilado toda esta información y también por haberse erigido en el auténtico promotor de la restauración y puesta en valor del cuadro. 


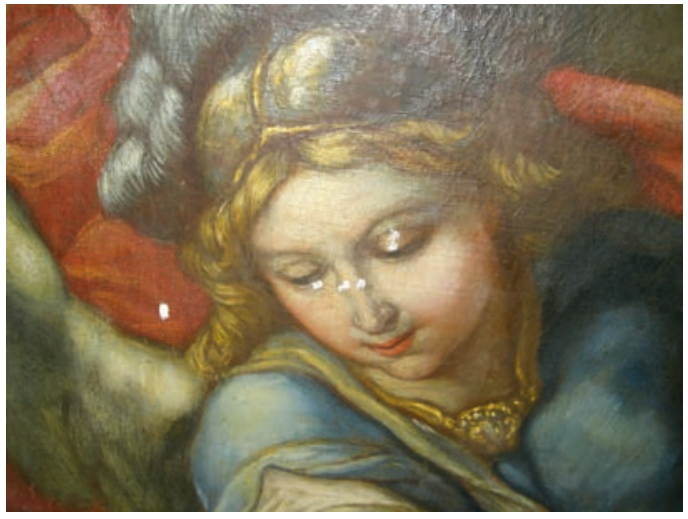

- Fig. 7. Giacomo Farelli. San Miguel Arcángel venciendo al Demonio. Pérdidas pictóricas detectadas durante el proceso de restauración (detalle). Foto de Julia Corral y Lucía Fernández.

intervenciones anteriores. Sólo en los puntos en los que la pérdida de la capa pictórica era muy elevada, se procedió a su estucado y reintegración cromática con acuarela. El bastidor, por su parte, fue reforzado con anclajes móviles y nuevos listones de madera blanda, con el fin de amortiguar su holgura con respecto al lienzo. Este último, por fin, se reinsertó en el marco, que fue reparado, desinsectado y sometido a limpieza, además de reponerle todas las cuñas y reintegrarle tanto la pintura rojiza como el pan de oro. Todo el proceso fue minuciosamente documentado mediante fotografías (Figs. 7 y 8), análisis con luz ultravioleta y una memoria escrita que ha sido consultada para escribir estas líneas ${ }^{36}$.

A modo de conclusión, podemos decir que el hallazgo y posterior restauración de este cuadro han permitido rescatar la figura de Giacomo Farelli, un artista prácticamente desconocido en España. Su obra tiene, desde luego, un notable interés para comprender la evolución de la Pintura Napolitana del siglo XVII, de la que este San Miguel Arcángel es una síntesis reveladora. En este artículo hemos analizado la obra desde diferentes puntos de vista: formal, iconográfico, biográfico y sociocultural. También hemos in-

${ }^{36}$ L.FERNÁNDEZ CENDEJAS Y J. CORRAL LEAL, Informe técnico de Restauración. San Miguel Arcángel, Alcalá de Henares, 2014, documento inédito. tentado indagar sobre su historia particular, proponiendo una hipótesis verosímil sobre su presencia en el Colegio de las Madres Irlandesas de Zalla, donde se encontraba a principios del siglo $\mathrm{XX}$, y documentando su posterior traslado a la Casa Provincial de los Hermanos Maristas en Alcalá de Henares. Esperamos haber contribuido a poner en valor una pieza notable que desde luego enriquece nuestro patrimonio histórico-artístico.

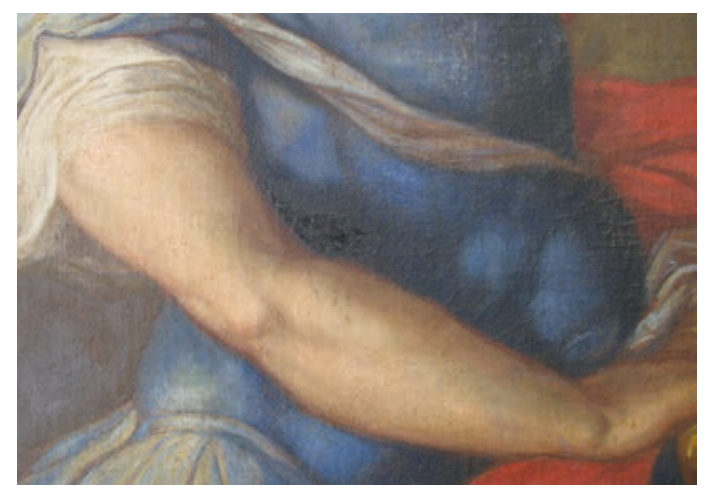

- Fig. 8. Giacomo Farelli. San Miguel Arcángel venciendo al demonio. Estado de conservación previo a su restauración (detalle). Foto de Julia Corral y Lucía Fernández.

\section{BIBLIOGRAFÍA}

AMBROSINI, A. La decorazione ad affresco nel palazzo del Comune di Pisa, in Palazzo Gambacorti a Pisa. Un cantiere in restauro, Venezia, 1998.

ARTNET, "Giacomo Farelli (Italian, 16241706). Auction results" (en línea), consultado el 20 de marzo de 2017. URL: http:// www.artnet.com/artists/giacomo-farelli/ past-auction-results

ASCIONE, G. C., "L'attivita del pittore Giacomo Farelli in Abruzzo", Atti del VI Convegno: Gli Acquaviva d'Aragona duchi di Atri e conti di S. Flaviano, Teramo, 1985, pp. 149-158.

BURKE, M. B. y CHERRY, P., Collections of Paintings in Madrid, 1601-1755, Los Angeles, 1997.

CAMPOS Y FERNÁNDEZ DE SEVILLA, F. J. (coord.), Actas del Simposio El Monasterio 
de El Escorial y la Pintura (San Lorenzo de El Escorial, noviembre de 2001), El Escorial, 2001.

CATELLO, C. y CATELLO, E. La cappella del tesoro di San Genaro, Napoli, 1977.

CAUTELA, G., MAURO, L. di, RUOTOLO, R. y SPINOSA, N., Napoli sacra. Guida alle chiese della città, Napoli, 1993-1997.

CROPPER, E., The Domenichino affair, New Haven, 2005.

DEGRAZIA BOHLIN, D., Prints and Related Drawings by the Carracci Family: a Catalogue Raisonne, Washington, 1979.

DELFINO, A., "Documenti inediti sui pittori del '600”, en Ricerche sul '600 napoletano, Milano, 1988.

DOMINICI, B. de, Vite de' pittori, scultori ed architetti napoletani, Napoli, 1743. Edizione commentata a cura di F. Sricchia Santoro e A. Zezza, vol. III, pp. 867-883, Napoli, 2008.

FERNÁNDEZ CENDEJAS, L. Y CORRAL LEAL J., Informe técnico de Restauración. San Miguel Arcángel, Alcalá de Henares, 2014, documento inédito.

FERRANDO ROIG, J., Iconografía de los Santos, Barcelona, 1950.

THE FITZWILLIAM MUSEUM, "God the Father, holding the dead Christ, in Glory, adored by Angels and St. John the Evangelist, St. Luke, St. Andrew, St. Mark? (or Jerome?), St. Ignatius Loyola and an unidentified male saint" (en línea), consultado el 20 de marzo de 2017. URL: http:// webapps.fitzmuseum.cam.ac.uk/explorer/index.php?oid $=6890$

GALLICHI SCHWENN, I., “Note su Giacomo Farelli pittore napoletano del seicento", Partenope, vol. I, 1961, pp. 200-213.

GIORGI, R., Santos, Barcelona, 2004.

GOOGLE ART PROJECT, Farelli, Giacomo - Apotheosis of a Female Saint (en línea), consultado el 20 de marzo de 2017. URL: https://commons.wikimedia.org/wiki/
File:Farelli,_Giacomo_-_Apotheosis_ of_a_Female_Saint_-_Google_Art_Project.jpg.

GREGORI, M. y SCHLEIER, E., La pittura in Italia. Il Seicento, Milano, 1989.

HERMOSO CUESTA, M., Lucas Jordán y la Corte de Madrid, una década prodigiosa (1692-1702), Zaragoza, 2008.

INTXAUSTI, J. (ed.), Actas del Primer Congreso de Historia de las familias e Institutos Religiosos en el País Vasco y Navarra, Arantzazu, 2002.

LATTUADA, R., "Farelli tra Abruzzo e Napoli: nuove opere e note sullo sviluppo stistico", en R. TORLONTANO, Abruzzo. Il barocco negato: aspetti dell'arte del Seicento e del Settecento, Roma, 2010, pp. 187-196.

LOUZAO VILLAR, J., Soldados de la fe o amantes del progreso: Catolicismo y modernidad en Vizcaya (1890-1923), Logroño, 2011.

Luca Giordano y España, Catálogo de la exposición, Madrid, 2002.

LUCIANI, O., Il Ciclo pittorico di Giacomo Farrelli nel Santuario di Maria SS della Croce di Roio esprime aspetti devozionali mariani del suo tempo (en línea), consultado el 20 de marzo de 2017. URL: http://oresteluciani.eu/GiacomoFarrelli.pdf.

MÂLE, E., El arte religioso de la Contrarreforma, Madrid, 2001.

MINIERI-RICCIO, C., Memorie storiche degli scrittori nati nel Regno di Napoli, Napoli, 1844.

MONTERA, R., "Gli affreschi di Giacomo Farelli nella Sala delle Baleari di Palazzo Gambacorti", Rassegna del Comuni di Pisa, 1972 , no $3-4$, pp. $18-22$, no 5-6, pp. 22-26, nº 7-9, pp. 35-39.

THE MORGAN LIBRARY \& MUSEUM, "Giacomo Farelli" (en línea), consultado el 20 de marzo de 2017. URL: http:// www.themorgan.org/search/site/farelli.

MUÑOZ GONZÁLEZ, M. J., El mercado español de pinturas en el siglo XVII, Madrid, 
2008.

NAVARRETE PRIETO, B., La pintura andaluza del siglo XVII y sus fuentes grabadas, Madrid, 1998.

OSTOLAZA ESNAL, M., Entre religión y modernidad: los colegios de las Congregaciones Religiosas en la construcción de la sociedad guipuzcoana contemporánea, 1876-1931, Leioa, 2000.

PACCIAROTTI, G., La pintura barroca en Italia, Madrid, 2000.

PAVONE, M. A., "The master of Christ and the adulteress, a precedent for the early work of Farelli", Prospettiva. Rivista di Storia dell Arte Antica e Moderna, no 57-60, 1990, pp. 265-272.

"Farelli, Giacomo", en Dizionario Biografico degli Italiani, Vol. 44. Roma, 1994 (en línea), consultado el 20 de marzo de 2017. URL: http://www.treccani.it/enciclopedia/giacomo-farelli_(Dizionario_Biografico)/

PÉREZ SÁNCHEZ, A. E., Pintura italiana del siglo XVII en España, Madrid, 1965.

PERSICO ROLANDO, E., "La decorazione affrescata di alcuni sottarchi nella Chiesa del Gesù Nuovo a Napoli. Aggiunte a Giacomo Farelli", Campania Sacra, XXXIII, no 1-2, 2002, pp. 230-231.

PIANE, S., Restauro Sala delle Baleari: presentato ieri alla stampa "Il Trionfo delle Baleari" di Giacomo Farelli (en línea), consultado el 20 de marzo de 2017. URL: http://cultura. comune.pisa.it $/ \mathrm{p}=1928$.

PINTO, R., La pittura napoletana, Napoli, 1998.

PORZIO, G., Sollevando il velo del tempo. Dipinti del Cinque e Seicento, Napoli, 2015.

POLERÓ y TOLEDO, V., Catálogo de los cuadros del Real Monasterio de San Lorenzo, llamado del Escorial, Madrid, 1857.

RAGIONE, A. della, Giacomo Farelli Opera Completa, Napoli, 2011.
RAUCCI, L., Giacomo Farelli pittore, Tesis Doctoral defendida en la Università degli studi di Napoli, 2003.

"Il cavalier Giacomo Farelli, un pittore tra Napoli e l'Abruzzo", Napoli nobilissima: rivista di arti, filologia e storia, $\mathrm{n}^{\mathrm{o}} 3-4$, 2004, pp. 93-104.

"Giacomo Farelli in Abruzzo", en R. TORLONTANO, Abruzzo. Il barocco negato: aspetti dell'arte del Seicento e del Settecento, Roma, 2010, pp. 166-171.

RÉAU, L., Iconografía del arte cristiano. Iconografía de la Biblia, Antiguo testamento, Tomo 1, vol. 1, Barcelona, 1996.

ROSELLI, G., Premessa alla II edizione, en P. Sarnelli, Guida de' forestieri, curiosi di vedere, e di riconoscere le cose più memorabili di Pozzuoli, Baja, Cuma, Miseno, Gaeta, ed altri luoghi circonvicini, Napoli, 1697.

ROYO RUIZ, M. A., Zalla. Estudio históricoartístico, Bilbao, 1997.

RUOTOLO, R., Mercanti collezionisti a Napoli: Gaspare Roomer e $i$ Van den Eynden, Meta di Sorrento, 1982.

RUOTOLO, R. y NIEGO, A., S. Brigida, Napoli, 1978.

SPINOSA, N., La pittura napoletana del '600, Napoli, 1984.

"La pittura del Seicento nell'Italia meridionale", en La pittura in Italia. Il Seicento, vol. I, Milano, 1989.

Pittura del Seicento a Napoli, da Mattia Preti a Luca Giordano, Napoli, 2011.

SPINOSA, N. y PÉREZ SÁNCHEZ, A. E. (coords.), Seicento Napoletano. Del Naturalismo al Barroco, Catálogo de la exposición Madrid, 2008.

SRICCHIA SANTORO, F. y ZEZZA, A., Marco Pino: un protagonista della maniera moderna a Napoli, Napoli, 2003.

STRAZZULLO, F. La Real Cappella del tesoro di San Genaro: documenti inediti, Napoli, 1978. 
THIEME, U. y BECKER, F., Allgemeines Künstler-Lexikon. Die Bildenden Künstler aller Zeiten und Völker, edición de K. G. Saur, München, 2003.

TURNER, J., The Dictionary of Art, New York, 1996.

VACCARO, M., "Alcune tele inedite di Giacomo Farelli in Abruzzo", Bollettino d'arte, no 98, 17, 2013, pp. 95-104.

WITTKOWER, R., Arte y arquitectura en Italia, 1600-1750, Madrid, 1992.

YETANO LAGUNO, A., "Las Congregaciones religiosas femeninas en el XIX. El tema de la obtención de su nuevo esta- tuto jurídico canónico y su interés historiográfico", Spagna Contemporanea, $\mathrm{n}^{\mathrm{o}} 36$, 2009, pp. 13-43.

ZARCO-BACAS Y CUEVAS, E. J., El monasterio de Sn. Lorenzo el Real de El Escorial, y la Casita del Príncipe, Madrid, 1926.

ZEZZA, A., Marco Pino: l'opera completa, Napoli, 2003.

“Une histoire de l'art sans héros? Études récentes sur la peinture napolitaine du XVIIe siècle", Perspective, actualité en histoire de l'art, 2011, pp. 435-459 (en línea), consultado el 25 de marzo de 2017. URL: https://perspective.revues.org/973. 